\title{
O TERMO DE AJUSTAMENTO DE GESTÃO COMO FORMA DE TUTELA DE DIREITOS SOCIAIS: O CASO DO TRIBUNAL DE CONTAS DO ESTADO DE SERGIPE
}

\section{THE MANAGEMENT ADJUSTMENT AGREEMENT AS A FORM OF GUARANTEE OF SOCIAL RIGHTS: THE CASE OF THE COURT OF ACCOUNTS OF THE STATE OF SERGIPE}

\section{PATRÍCIA VERÔNICA NUNES CARVALHO SOBRAL DE SOUZA}

Doutora em Direito Público pela Universidade Federal de Bahia (UFBA). Doutora em Educação e Mestra em Direito pela Universidade Federal de Sergipe (UFS). Especialista em Direito do Estado e Especialista em Direito Municipal (UNIDERP). Especialista em Direito Civil e Processo Civil pela Universidade Tiradentes (UNIT). Especialista em Auditoria Contábil pela Universidade Federal de Sergipe (UFS). Professora de Graduação e Pós-graduação da Universidade Tiradentes (UNIT). Diretora Técnica do Tribunal de Contas do Estado de Sergipe. E-mail: patncss@gmail.com.

IRENE PORTELA

Doutora em Direito Constitucional pelo departamento de Direito Público e Teoria do Estado, pela Universidade de Santiago de Compostela. Mestre em Administração Pública, pela Universidade do Minho. Pós-graduada em Direito da Comunicação, pelo Instituto Jurídico da Comunicação, Faculdade de Direito da Universidade de Coimbra. Exerce vários cargos na Escola Superior de Gestão do IPCA, tendo sido até à data a docente responsável pela Unidade Curricular de Direito Constitucional e de Direitos Fundamentais, aos cursos de Solicitadoria e de Fiscalidade. 


\section{RESUMO}

Objetivo: O presente artigo parte da construção de uma conjectura que sonda as possibilidades de um Termo de Ajustamento de Gestão no ambiente dos Tribunais de Contas, mostrando-se benéfico ou não à sociedade por meio da sua prática consensual. A pesquisa busca a possibilidade e a necessidade de comprovar se 0 Termo de Ajustamento de Gestão atua com o objetivo primordial de beneficiar a sociedade como instrumento de tutela de direitos fundamentais sociais.

Metodologia: Uma abordagem qualitativa, por entendê-la como um instrumento de exploração de um fenômeno, para compreender o significado que indivíduos ou grupos Ihes conferem, especialmente, no ambiente social ou humano. Utiliza-se a revisão bibliográfica de caráter exploratório, descritivo e documental, uma vez que a mesma possibilita sumarizar as revisões bibliográficas com a finalidade de aprofundar o objeto de estudo através dos processos e documentos oriundos do Tribunal de Contas Sergipano.

Resultados: O Termo de Ajustamento de Gestão, por sua própria essência, continua, na sua aplicação, como um instrumento importante do ativismo administrativo, posto que permite por meio de compromissos firmados no seu bojo, ir além do que a lei literalmente dispõe, cuja finalidade volta-se para a concretização de direitos dos cidadãos e em benefício desses, indo além da literalidade da lei, levando-se em consideração que o julgador de contas não detém o conhecimento absoluto acerca de todos os fatos que circundam a Pública Administração, sejam eles de ordem técnica, científica e orçamentária entre outras. O Termo de Ajustamento de Gestão revela-se como um instrumento consensual, decorrente de inspeções e auditorias realizadas pelos Tribunais de Contas, cujo estudo apresentou 68 Termos de Ajustamento de Gestão firmados pelo Tribunal de Contas do Estado de Sergipe (TCE/SE) e órgãos municipais/estaduais na perspectiva de corrigir rumos e tutelar direitos sociais fundamentais.

Contribuições: Este estudo permite compreender a necessidade de se (re)pensar a gestão pública ultrapassando os limites dos tradicionais mecanismos do direito administrativo, onde se afirma o caráter democrático, educativo e pedagógico do Termo de Ajustamento de Gestão como prática preventiva ou saneadora de irregularidades. Também a título de contribuição, assinala-se a premência de um maior dinamismo na ação e solução de conflitos que não tenham como última finalidade a sanção, e sim a recomposição e a reorganização da gestão, buscando a correta implementação de políticas públicas que se voltem efetivamente à coletividade.

PALAVRAS-CHAVE: Ativismo de contas; Termo de Ajustamento de Gestão (TAG); Tribunal de Contas; tutela de direitos sociais. 


\begin{abstract}
Objective: This article starts from the construction of a conjecture that probes the possibilities of a Management Adjustment Term in the environment of the Courts of Auditors proving to be beneficial or not to society by way of its consensual practice. The research seeks the possibility and the need to prove whether the Management Adjustment Term acts with the primary objective of benefiting society as an instrument of protection of fundamental social rights.
\end{abstract}

Methodology: A qualitative approach, to understand it as an instrument for exploring a phenomenon, to understand the meaning that individuals or groups give them, especially in the social or human environment. An exploratory, descriptive and documentary bibliographic review is used, as it makes it possible to summarize the bibliographic reviews in order to deepen the object of study through the processes and documents originating from the Court of Auditors of the State of Sergipe, Brazil.

Results: The Term of Management Adjustment, by its very essence, continues in its application as an important instrument of administrative activism, as it allows by way of commitments signed in its core, to go beyond what the law literally provides, which target is to achieve citizens' rights and for their benefit, going beyond the literality of the law and taking into account that the auditor does not have absolute knowledge about all the facts surrounding the Public Administration, whether technical, scientific or budge among others. The Term of Management Adjustment reveals itself as a consensual instrument resulting from inspections and audits carried out by the Audit Courts, which study presented 68 Terms of Management Adjustment signed by the Audit Courts of the State of Sergipe (TCE/SE) and municipal /state bodies in the perspective of correcting directions and protecting fundamental social rights.

Contributions: This study allows us to understand the need to (re)think public management beyond the limits of the traditional mechanisms of administrative law, which affirms the democratic, educational and pedagogical character of the Term of Management Adjustment as a preventive or remedy for irregularities. Also as a contribution, there is an urgent need for greater dynamism in the action and resolution of conflicts that do not have the ultimate purpose of sanction, but rather the recomposition and reorganization of management seeking the correct implementation of public policies effectively directed to the community.

KEYWORDS: Account activism; Term of Management Adjustment (TAG); Audit Office; protection of social rights. 


\section{INTRODUÇÃO}

No vórtice sócio histórico e político-econômico vivenciado pelo Brasil, conceitos, definições e instituições requerem novos e reflexivos olhares em busca da compreensão e interpretação de fatos que se sucedem cotidianamente. Este estudo quer aprofundar, deter o olhar e tentar desvelar a correlação do Termo de Ajustamento de Gestão (TAG) e a sua tutela quanto a direitos sociais fundamentais e, no mais específico, examinar se o TAG se manifesta como prática ativista dos Tribunais de Contas.

Com a atenção direcionada ao Estado brasileiro, o viés ideológico da Constituição da Republicana de 1988 manifesta-se através de um texto de conteúdo programático, futurista, que ressalta a dignidade da pessoa humana como condutor da atuação estatal, de elaboração legislativa e hermenêutica, sem, diante de tais fatores, abandonar o sistema capitalista na concretude dos direitos de propriedade e da livre iniciativa (princípio fundamental do liberalismo) e, inserindo, para a efetivação do desenvolvimento econômico, um rol de direitos sociais e individuais.

Desde a redemocratização do país, com efeito, os termos "Constitucionais" e "Estado de Direito" continuam sendo pedras fundamentais da cidadania, propulsoras da participação, da transparência e do ativismo, ou seja, o cidadão ativista é aquele que age no social. O termo ativista, empregado aqui, não é essencialmente no sentido de ativismo político-partidário.

Destarte, a presente pesquisa tem como objeto de estudo o TAG - Termo de Ajustamento de Gestão e sua aplicação por alguns Tribunais de Contas pátrios como possibilidade de prática ativista de controle externo e de tutela de direitos sociais.

A justificativa para esta investigação teórica se encontra na evidente importância dos aspectos de controle externo exercidos pelos Tribunais de Contas quando se utiliza do TAG, apresentando uma abordagem preventiva e pedagógica.

Em conformidade com o objeto de estudo e com a justificativa acima, apresenta-se como o objetivo geral deste artigo desvelar o Termo de Ajustamento de Gestão (TAG), quanto à tutela de direitos sociais fundamentais. 
No que se refere ao problema que se apresenta na pesquisa, este consubstancia-se na análise de estudo de caso dos TAGs firmados no TCE/SE quanto à tutela de direitos sociais fundamentais.

Frente a esses esclarecimentos, optou-se pelas pesquisas exploratória e descritiva. Exploratória, por explorar as nuances do TAG, adotado por alguns Tribunais de Contas, especificamente o Tribunal de Contas de Sergipe, com o objetivo de facilitar a delimitação do tema desta pesquisa; direcionar à fixação das finalidades e a elaboração das hipóteses ou encontrar uma nova forma de enfoque para o assunto. Ainda assim, por buscar encontrar as respostas ao problema identificado. Descritiva, porque apresenta as características do fenômeno, como também estabelece relações entre outros fenômenos, além de viabilizar um detalhamento sobre a situação que se propõe a pesquisar, percebendo o que está ocorrendo, bem como o seu funcionamento.

A metodologia aplicada é de abordagem qualitativa, por entendê-la como um instrumento de exploração de um fenômeno, para compreender o significado que indivíduos ou grupos lhes conferem, especialmente, no ambiente social ou humano. Utiliza-se de revisão bibliográfica de caráter exploratório, descritivo e documental, uma vez que a mesma possibilita sumarizar as revisões bibliográficas, com a finalidade de aprofundar o objeto de estudo através dos processos e documentos oriundos da Corte de Contas Sergipana.

Nesse sentido, parte-se da construção de uma conjectura que sonda as possibilidades de o Termo de Ajustamento de Gestão, no ambiente dos Tribunais de Contas, mostrar-se benéfico ou não, à sociedade através da sua prática consensual. Isto é: seria possível e necessário comprovar que o Termo de Ajustamento de Gestão atua com o objetivo primordial de beneficiar a sociedade, como instrumento de tutela de direitos fundamentais sociais?

Vale destacar que esta pesquisa é um recorte da tese de doutoramento desenvolvida no contexto do Programa do Doutorado em Direito Público da Universidade Federal da Bahia (UFBA), intitulada "O Termo de Ajustamento de Gestão como forma de tutela de Direitos Sociais: o caso do Tribunal de Contas do Estado de Sergipe". 
Diante desse prisma, é essencial compreender a necessidade de se (re) pensar a gestão pública ultrapassando os limites dos tradicionais mecanismos do direito administrativo, onde se afirma o caráter democrático, educativo e pedagógico do TAG, como prática preventiva ou saneadora de irregularidades. É assinalada também a premência de um maior dinamismo na ação e solução de conflitos, que não tenham como última finalidade a sanção, e sim a recomposição, a reorganização da gestão, buscando a correta implementação de políticas públicas que se voltem efetivamente à coletividade. Assim, TAG revela-se como um instrumento consensual, decorrente de inspeções e auditorias realizadas pela Cortes de Contas, cujo estudo apresentou 68 (sessenta e oito) TAGs firmados pelo TCE/SE e órgãos municipais/estaduais na perspectiva de corrigir rumos e tutelar direitos sociais fundamentais.

\section{O TERMO DE AJUSTAMENTO DE GESTÃO (TAG) COMO NOVA FORMA DE PENSAR DOS TRIBUNAIS DE CONTAS}

Com a CF/88 e o advento da EC 19/1998 urgiu se reflexionar acerca da nova forma de gestão pública, com vistas a ultrapassar os tradicionais instrumentos do Direito Administrativo, pautados no ideal de supremacia e de controle do ato administrativo, cujo foco residia, notadamente, na esfera formal-legalista da máquina estatal.

A Constituição de 1988 é o ápice do retorno da democracia no Brasil. Com efeito, nunca uma Constituição no Brasil conseguiu se aproximar das forças efetivas do poder. Paulo Bonavides (2004) assinala que o que ocorreu foi uma alteração de transição discricionária para transição constitucional. Assim ocorreu a transferência de um governo autoritário para um democrático, composto de três poderes.

Novos instrumentos administrativos, trouxeram a necessidade de uma administração pautada em resultados, a fim de concretizar e promover, por meio da eficiência e dos princípios norteadores da Administração Pública, o sistema axiológico de garantias constitucionais, especialmente quanto aos Direitos Fundamentais, como 
exemplos dos contratos de gestão, das parcerias público-privadas, do credenciamento de pessoas jurídicas sem fins lucrativos (organizações sociais e organizações de interesse da sociedade civil) e etc.

Esta nova concepção de Administração Pública por resultado fundou-se na efetivação da eficácia econômica e técnica, da transparência, da tempestividade, da qualidade versus quantidade das ações governamentais. Neste argumento, para que a Administração alcançasse os resultados almejados, se fez necessário adotar mecanismos de controle consensual em contraponto a genuína supremacia estatal.

Nesse encalço, exige-se pensar em meios de retificar e/ou evitar falhas, inutilizando métodos punitivos e aplicando a prevenção, a reforma, a reorganização da gestão, com o intuito precípuo de implementar um adequado controle social. É neste viés que o Termo de Ajustamento de Gestão advém como ferramenta para promover a melhoria da gestão da Administração Pública, utilizando-se do consenso como base salutar.

A adoção dos Termos de Ajustamento de Gestão - TAG, por Tribunais de Contas, como forma de controle consensual da Administração, requer a um ajuste de interesses entre controlador e controlado, através do qual este se obriga ao fiel cumprimento da lei, em prol do alcance da efetividade da política pública, deixando de ser puramente sancionador, apresentando viés de conciliador.

Assim, a solução de conflitos, entendida como consensual, necessita de um tratamento igualitário, menos complexo e mais efetivo e célere. Na presente pesquisa, se suscita sua adoção na esfera dos Tribunais de Contas com o fim primordial de tutelar direitos sociais.

Os direitos sociais são definidos como os que têm por finalidade assegurar à população meios materiais compreendidos como necessários para seu pleno gozo. Por tal motivo, tais direitos acabam por requerer junto ao Estado uma intervenção na ordem social que garanta os requisitos de justiça distributiva, com o fito de reduzir as desigualdades sociais.

O artigo 6을 da Carta Magna de 1988 (BRASIL, 2010a) refere-se de forma genérica aos direitos sociais, compreendidos como direito à saúde, à educação, à 
transparência, ao trabalho, ao lazer etc. Disto extrai-se que os direitos sociais objetivam a qualidade de vida dos cidadãos.

Como o Estado detém a função precípua de mediador para a solução de conflitos, este deve adotar ações positivas para suprir as necessidades decorrentes do contínuo desenvolvimento social. Tal pensamento tem como reforço a Declaração de Direitos de Virgínia, EUA, que estabelece em seu art. 3ํ:

\footnotetext{
Governo é ou deve ser instituído para o bem comum, para a proteção e segurança do povo, da nação ou da comunidade. Dos métodos ou formas, o melhor será que se possa garantir, no mais alto grau, a felicidade e a segurança e o que mais realmente resguarde contra o perigo de má administração (WILLIAMSBURG, 1776, p. 1).
}

Neste cenário, as formas de atuação do controle da Administração Pública carecem de adaptação ao um novo contexto social, não podendo condicionar seu exercício apenas ao controle-sanção, ultrapassando os limites de atribuição, aprovação ou reprovação da prestação de contas. Isto é, deve-se utilizar outros mecanismos que possibilitem a transação de objetivos entre o controlador e o controlado, substituindo ou reduzindo o caráter punitivo, resultando na reparação da política pública que poderá tutelar direitos sociais, com consequente benefício em prol da sociedade e este é o grande papel dos TAGs: transigir ao invés de unicamente sancionar.

\subsection{CONCEITO, FINALIDADES E NATUREZA JURÍDICA DO TAG}

Os TAGs têm na sua criação e inspiração os termos de ajuste de conduta que são deferidos por lei ao Ministério Público e que possuem os mesmos objetivos: elidir um processo e funcionar também pedagogicamente com correção de rumos, sem a aplicação de sanções, que só seriam necessárias em não sendo o TAC cumprido pela parte signatária do mesmo. Logo, se faz pertinente uma pequena digressão acerca do Termo de Ajustamento de Conduta (TAC), do Ministério Público, que ocorre na fase pré-processual. 
O termo de ajustamento de conduta foi oriundo inicialmente do art. 211 da Lei n. 8.069/90 (estatuto da criança e do adolescente) e do Código de Defesa do Consumidor (Lei 8.078, de 11/09/1990), que em seu artigo 113 estabeleceu o acréscimo do $\S 6^{\circ}$ ao art. 5, da Lei 7.347/85 (Lei de Ação Civil Pública). Estes ditames legais modificaram a lei de ação civil pública (7.347/85), assegurando a efetividade do termo de ajustamento de conduta aos direitos coletivos lato sensu. Sem olvidar do contido no art. 174, III, do Código de Processo Civil ${ }^{1}$ que prevê a sua possibilidade e, mais recentemente, com o estabelecido, em norma infraconstitucional de cunho especificamente administrativo, Lei $13.655 / 2018^{2}$, em seu art. 26 , em que a autoridade administrativa pode celebrar compromisso com os interessados.

O termo de ajustamento de conduta, como já dito, é uma técnica alternativa extrajudicial para solucionar conflitos presentes na fase do inquérito civil ou em procedimentos administrativos. O termo compromete o infrator em assumir a responsabilidade de enquadrar sua conduta ao ordenamento jurídico perante o agente público, sob pena de sanção em caso do não cumprimento (BORBA, 2012).

A antiga ideia de um controle exclusivamente revestido de caráter sancionatório da atividade da administração pública e o ordenamento jurídico com essência positivista, em que o administrador deverá seguir a estrita letra da lei, foi cedendo espaço, em meados do século XX, aos novos mecanismos e concepções de gestão na busca pela aquisição da eficiência da máquina estatal, através da

\footnotetext{
${ }_{1}^{1}$ A União, os Estados, o Distrito Federal e os Municípios criarão câmaras de mediação e conciliação, com atribuições relacionadas à solução consensual de conflitos no âmbito administrativo, tais como: I - dirimir conflitos envolvendo órgãos e entidades da administração pública; II - avaliar a admissibilidade dos pedidos de resolução de conflitos, por meio de conciliação, no âmbito da administração pública; III - promover, quando couber, a celebração de termo de ajustamento de conduta.

${ }^{2}$ Art. 26. Para eliminar irregularidade, incerteza jurídica ou situação contenciosa na aplicação do direito público, inclusive no caso de expedição de licença, a autoridade administrativa poderá, após oitiva do órgão jurídico e, quando for o caso, após realização de consulta pública, e presentes razões de relevante interesse geral, celebrar compromisso com os interessados, observada a legislação aplicável, o qual só produzirá efeitos a partir de sua publicação oficial. § 10 compromisso referido no caput deste artigo: I - buscará solução jurídica proporcional, equânime, eficiente e compatível com os interesses gerais; II - (VETADO); III - não poderá conferir desoneração permanente de dever ou condicionamento de direito reconhecidos por orientação geral; IV - deverá prever com clareza as obrigações das partes, o prazo para seu cumprimento e as sanções aplicáveis em caso de descumprimento.
} 
necessidade de promover as normas em cumprimento às demandas sociais (FERRAZ, 2010, p. 209).

O que ocorre é o afastamento do positivismo clássico, desapoderando a percepção da função de controle somente como 'sanção', da exaltação do princípio da legalidade em sentindo estrito, em que a máquina administrativa se prenderá a execução seca da letra da lei, abrindo margem a reflexão acerca da necessidade de alcançar e aproximar elementos relevantes tanto na esfera jurídica, quanto na esfera administrativa, isto é, os fatos (condições de atuação) às normas jurídicas postas e os procedimentos às demandas da sociedade, respectivamente (SOBRAL DE SOUZA, 2013, p. 111).

Neste caminho de uma Administração Pública ordenada no ideal do agir consensual, percebe-se a transformação e adequação da máquina administrativa em relação aos administrados, através de adoção de mecanismos de solução de conflitos, promovendo e aproximando a sociedade da efetiva gestão. No contexto de controle consensual, insere-se o Termo de Ajustamento de Gestão (TAG) como ferramenta moderna de prevenção diante de uma concreta ou eventual violação de caráter não doloso à norma, adotado por Tribunais de Contas.

A este ideal, primordialmente, foi elaborado o TCG - Termo de Compromisso de Gestão, como um mecanismo de controle consensual, aplicado inicialmente pelo

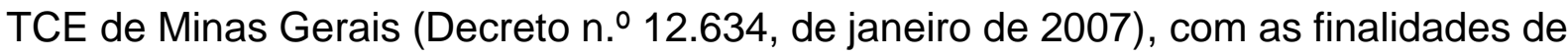
promover a celeridade nas decisões, a oitiva democrática dos gestores e a consensualidade (evitando litígios e processos intermináveis) e, ainda, para implementar o controle não com natureza punitiva e/ou de arrecadação de recursos, e sim para assegurar a excelência na gestão pública. Com o fito de prevenir ou corrigir os rumos da Administração, sem a necessária aplicação coercitiva da lei.

Para Ferraz (2010), o TAG afilia-se ao moderno movimento da Administração Pública e do Direito Administrativo, com menor natureza autoritarista e maior caráter convencional, revestindo-o da noção do existir consensual, de forma alternativa, em troca da imperatividade, quer dizer, em substituição, se cabível à aplicação da ação coercitiva. Para ele, o Termo de Ajustamento de Gestão atua como controle consensual da Administração Pública, como método jurídico para concretizar, na 
esfera do Direito, a prevenção que estabelece o art. $59, \S 1^{\circ}$, da $\mathrm{LRF}^{3}$. Isto reafirma que a Corte de Contas pode, de logo, transpor essa 'fase' e obter-se da implementação do aludido no art. 71 , IX, X e Xl e, ainda, nos $\S \S 1^{\circ}$ e $2^{\circ}$ da CF/884.

O termo de ajustamento de gestão tem como princípios norteadores: a boafé, a eficiência e a consensualidade - posto que não há de se falar de um TAG para o mau gestor, mas para aquele cometeu falhas, impropriedades, sem a intenção deliberada do dolo.

A ferramenta propicia a abertura de espaços democráticos para os envolvidos, conforme a teoria do filósofo Habermas- dos falantes, com base no consenso, pois tanto a Administração Pública. Quanto os TCs, este se manifestará através de um mecanismo extrajudicial denominado negociação, sempre através do agir comunicativo, visto que o TAG também se alinha na Teoria de Jungem Habermas, que se funda em três alicerces: na sinceridade, na verdade e na correção normativa, qualidades essenciais de um gestor de boa-fé. E assim, o TAG evitará litígios e processos intermináveis, não apenas na seara administrativa, mormente no Judiciário.

\footnotetext{
${ }^{3}$ Art. 59. O Poder Legislativo, diretamente ou com o auxílio dos Tribunais de Contas, e o sistema de controle interno de cada Poder e do Ministério Público, fiscalizarão o cumprimento das normas desta Lei Complementar, com ênfase no que se refere a: I - atingimento das metas estabelecidas na lei de diretrizes orçamentárias; II - limites e condições para realização de operações de crédito e inscrição em Restos a Pagar; III - medidas adotadas para o retorno da despesa total com pessoal ao respectivo limite, nos termos dos arts. 22 e 23; IV - providências tomadas, conforme o disposto no art. 31, para recondução dos montantes das dívidas consolidada e mobiliária aos respectivos limites; $V$ - destinação de recursos obtidos com a alienação de ativos, tendo em vista as restrições constitucionais e as desta Lei Complementar; VI - cumprimento do limite de gastos totais dos legislativos municipais, quando houver. $\S 1$ ㅇ Os Tribunais de Contas alertarão os Poderes ou órgãos referidos no art. 20 quando constatarem I - a possibilidade de ocorrência das situações previstas no inciso II do art. 40 e no art. 9o; II - que o montante da despesa total com pessoal ultrapassou $90 \%$ (noventa por cento) do limite; III que os montantes das dívidas consolidada e mobiliária, das operações de crédito e da concessão de garantia se encontram acima de $90 \%$ (noventa por cento) dos respectivos limites; IV - que os gastos com inativos e pensionistas se encontram acima do limite definido em lei; $V$ - fatos que comprometam os custos ou os resultados dos programas ou indícios de irregularidades na gestão orçamentária.

${ }^{4}$ Art. 71 . O controle externo, a cargo do Congresso Nacional, será exercido com o auxílio do Tribunal de Contas da União, ao qual compete: [...] IX - assinar prazo para que o órgão ou entidade adote as providências necessárias ao exato cumprimento da lei, se verificada ilegalidade; $X$ - sustar, se não atendido, a execução do ato impugnado, comunicando a decisão à Câmara dos Deputados e ao Senado Federal; XI - representar ao Poder competente sobre irregularidades ou abusos apurados. $\S$ $1^{\circ}$ - No caso de contrato, o ato de sustação será adotado diretamente pelo Congresso Nacional, que solicitará, de imediato, ao Poder Executivo as medidas cabíveis. § 2o - Se o Congresso Nacional ou o Poder Executivo, no prazo de noventa dias, não efetivar as medidas previstas no parágrafo anterior, o Tribunal decidirá a respeito.
} 
Habermas (1987) conceituou a teoria da ação comunicativa na busca do consenso (fator básico dos Termos de Ajustamento de Gestão), em torno da função das organizações e a empregou como instrumento substancial de análise da estrutura e do efetivo funcionamento dos conselhos de participação popular, característica das sociedades capitalistas ${ }^{5}$.

Como pode chegar ao consenso o Tribunal de Contas, no sentido de corrigir rumos da Administração Pública? A resposta pode ser encontrada dentro da filosofia de Habermas, diante da sua teoria do agir comunicativo. O consenso é condição sine qua non para a existência de um Termo de Ajustamento de Gestão, posto que este não se impõe, mas terá de ser a resultante de um acordo de vontades entre o órgão de controle e o gestor responsável pelos atos questionados.

Neste caso, os Tribunais de Contas que utilizam o TAG, o empregam como instrumento de consenso e solução de problemas para com as instituições públicas jurisdicionada, evitando, num primeiro momento, que haja penalidade imediata quanto a atos infracionais não dolosos. A sanção só seria aplicada, em último, se o gestor, se não cumprisse o pactuado no TAG.

Essa teoria dá possibilidade de resolução de conflitos na sociedade como uma melhor solução e não uma possível solução, pois ela abrange e tem como base o consenso dos envolvidos. Em seu livro "Direito e Democracia", Habermas, ao tratar de legitimação do direito, esclarece que esta ocorre por meio da democracia e a base da democracia é o agir comunicativo (HABERMAS, 1997).

Um outro aspecto, pautado na teoria do filósofo Michel de Certeau, em sua obra a invenção do cotidiano, foi quanto aos elementos estratégia e tática, vê-se que a estratégia sempre é própria do órgão de controle, da instituição, daquela que tem poder. Por outro lado, as táticas são os elementos necessários e fundamentais para

\footnotetext{
${ }^{5}$ Como representante da denominada Escola de Frankfurt, Habermas trouxe uma perspectiva através da qual lançou o seu olhar sobre a sociedade e que esta incorpora enfoques teóricos diferenciados e divergentes, sempre a partir do diálogo com as teorias e temáticas, quer do funcionalismo, da fenomenologia, do marxismo e etc. Assim, as reflexões Habermasianas são fixadas a partir do conjunto de teorias, construídas num processo complexo que se enriquece enquanto incorpora o diálogo já referenciado, produzindo um novo paradigma.
} 
a consecução, andamento e conclusão do TAG de forma satisfatória e consequentemente beneficie à coletividade.

O Termo de Ajustamento de Gestão, enfim, funciona e tem a sua definição como um ajuste de vontades firmado entre o controlador e o controlado, com propósitos que devem ser cumpridos, a fim de prevenir ou corrigir a inobservância de princípios e normas constitucionais e legais, de procedimentos, e da inexecução de políticas em prol do controle social, quer dizer, do não alcance de políticas estabelecidas.

\subsection{PREVISÃO LEGAL DO TAG E O ATIVISMO DE CONTAS}

É indubitável que o Estado não pode fugir da sua função essencial de promover a justiça social, conforme premissa suprema estabelecida pela Constituição da República Federativa de 1988. Sendo assim, não há de se falar da inconstitucionalidade do TAG, pois sendo ele uma espécie de consenso entre administrados e fiscalizados, otimiza a solução de conflitos, que é facultada pelo Preâmbulo da Carta federal, evitando processo longo, demorado que, por si só, fragiliza o controle externo da Pública Administração.

De fato, a Constituição Federal de 88 não traz expressamente em seu texto o Termo de Ajustamento de Gestão, daí o caráter imprescindível dos TAGs produzidos pelos Tribunais de Contas em decorrência dos poderes implícitos que thes são concedidos no art. 71da Lei Maior (BRASIL, 2010a). Deste modo, se torna possível a sua aplicação, como facilitador da concretização do ideal social, através do consenso nas decisões das Cortes de Contas, visto que na execução do controle externo, o Tribunal de Contas é responsável por determinar prazo para que órgão ou entidade sob seu controle adote providências necessárias ao cumprimento da lei, como se vê do art. 71, IX da Lei Maior (BRASIL, 2010a), pois trata de uma aceitação, via transversa, entre o Tribunal e o gestor, evitando, assim, num primeiro momento a imputação da sanção, que só será aplicada, se não forem cumpridas as determinações ali previstas. 
Os Tribunais de Contas, até então diante da inexistência de amparo regulatório, através da prática ativista, buscavam, de forma eficiente, sanar impropriedades de gestores públicos e minimizar eventuais danos à sociedade, utilizando-se do Termo de Ajustamento de Gestão, como meio preventivo, de modo a reparar práticas irregulares. Para tanto, o atual Código de Processo Civil ${ }^{6}$ brasileiro, em seu art. 174, inciso III, estabelece o termo de ajustamento de conduta, que simetricamente reforça as competências dos Tribunas de Contas quanto à utilização dos TAGs.

Mais recentemente, consolidando o entendimento do ativismo de contas e dos poderes implícitos conferidos aos TCs, considerando que CPC é norma de cunho geral e foi editada a Lei no $13.655 / 2018^{7}$ que incorpora na Lei de Introdução às Normas do Direito Brasileiro ${ }^{8}$ novos dispositivos de princípios gerais que devem ser seguidos em decisões advindas de órgãos públicos, como as do judiciário, do Ministério Público e dos Tribunais de Contas, robustecendo a atribuição de controle dos Tribunais de Contas, efetivando a segurança jurídica e a eficiência na elaboração e na aplicação do direito público, minimizando, assim, o grau de indeterminação das normas públicas e a instabilidade de atos jurídicos e administrativos., especialmente, através da regulação sobre a celebração de compromisso, com o objetivo de prevenir e/ou eliminar irregularidades.

$\mathrm{O}$ art. 26, parágrafo primeiro e incisos da lei em comento confere a possibilidade de a autoridade administrativa celebrar um acordo/compromisso com os particulares, em prol da extinção ou prevenção de impropriedades, incertezas jurídicas ou um litígio. Permitindo, deste modo, acordos administrativos diante de eventuais fatos contenciosos. Para o firmamento do compromisso, além dos requisitos

\footnotetext{
${ }^{6}$ Art. 174. A União, os Estados, o Distrito Federal e os Municípios criarão câmaras de mediação e conciliação, com atribuições relacionadas à solução consensual de conflitos no âmbito administrativo, tais como: [...] III - promover, quando couber, a celebração de termo de ajustamento de conduta (BRASIL, 2015).

7 Oriunda do Projeto de Lei oㅜ 7448/2017 de autoria do Senador Antônio Anastasia, sancionado em 25/04/2018, com 8 vetos.

${ }^{8}$ A Lei de Introdução às Normas do Direito Brasileiro, autônoma ou independente, abrange princípios determinativos da aplicabilidade das normas, casos de hermenêutica jurídica sobre direito privado e direito público, além de possuir normas de direito internacional privado.
} 


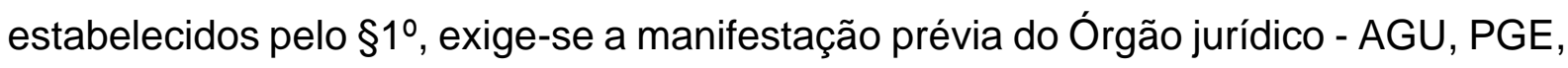
entre outros.

Assim, cumpre pontuar que a Lei 13.655/2018, igualmente, possibilita o firmamento do TAG, porém, não insere em seus dispositivos qualquer menção que os compromissos só podem ser pactuados em ações não dolosas, caraterística principal do TAG.

Disso extrai-se que os Tribunais de Contas orientarão os Poderes ou órgãos acerca de constatações e de irregularidades na administração respectiva, através da formalização do TAG $^{9}$ para apresentar as possibilidades de solução ou de saneamento dos danos relativos à sua gestão, aplicando a função pedagógica de conscientizar e prevenir, dispensando até então a figura da sanção.

Mas ultrapassada a questão da fundamentação legal, pode e se considera como prática ativista dos TCs quando este órgão de controle externo elenca elementos necessários para o fiel cumprimento daquele ato administrativo, daquela política pública, daquelas falhas ou irregularidades.

Lembrando o que ocorre nos EUA, é relevante a afirmação de que o ativismo judicial outra coisa não seria que "[...] a atuação da Corte em decisões fundadas em princípios e regras constitucionais, de defesa da Constituição contra as invasões, omissões e excessos dos outros poderes" (KOERNER, 2016, p. 242).

Para Barroso (2013) a noção de ativismo judicial está vinculada a participação expandida e profunda do Poder Judiciário na efetivação e concretização dos valores e objetivos constitucionais, diante da ampla intervenção no espaço de exercício dos demais poderes. Dessa forma, em maior parcela de fatos ocorre o preenchimento de espaços lacunosos.

Logo, é forçoso reconhecer-se que as Cortes de Contas, igualmente às Judiciárias, podem e devem praticar o ativismo de contas, posto que nem sempre 0 texto literal da lei conduz à melhor solução, não só para o controle externo da Pública

\footnotetext{
${ }^{9}$ Convém suscitar a relevância dos TAGs, que foi um dos itens de critérios de avaliação dos Tribunais de Contas do Brasil, em pesquisa do Marco de Medição de desempenho dos Tribunais de Contas ${ }^{9}$ (MMD/TCs), elaborado pelo Instituto Rui Barbosa. Esta avaliação, a nível nacional, busca promover avanços institucionais nos Tribunais e fomentar o sistema Tribunal de Contas como fundamental ao controle dos recursos públicos, à cidadania e estímulo à transparência das informações.
} 
Administração, bem como para o melhor uso dos recursos disponíveis, tornando-os eficazes no seu objetivo final. Para tanto é que surgem os TAGs que propiciam ao controlador as convicções mais viáveis de solução de conflitos onde não exista dolo ou má-fé, por parte do gestor, para mediante uma análise principiológica da lei se estabelecer ajustes para a correção de rumos das ações irregulares dos gestores públicos, conforme os princípios do direito administrativo.

\section{OS TRIBUNAIS DE CONTAS QUE ADOTARAM O TAG E OS QUE NÃO UTILIZAM O TAG}

Observa-se no Brasil um total de 33 (trinta e três) Tribunais de Contas, dentre eles (quadro 5 - Apêndice 2): 1 (um) Tribunal de Contas da União, 27 (vinte e sete) Tribunais de Contas dos Estados: Tribunal de Contas do Estado do Acre, Tribunal de Contas do Estado de Alagoas, Tribunal de Contas do Estado do Amapá, Tribunal de Contas do Estado do Amazonas, Tribunal de Contas do Estado da Bahia, Tribunal de Contas do Estado do Ceará, Tribunal de Contas do Estado do Espírito Santo, Tribunal de Contas do Estado de Goiás, Tribunal de Contas do Estado do Maranhão, Tribunal de Contas do Estado de Mato Grosso, Tribunal de Contas do Estado de Mato Grosso do Sul, Tribunal de Contas do Estado de Minas Gerais, Tribunal de Contas do Estado do Pará, Tribunal de Contas do Estado da Paraíba, Tribunal de Contas do Estado do Paraná, Tribunal de Contas do Estado de Pernambuco, Tribunal de Contas do Estado do Piauí, Tribunal de Contas do Estado do Rio de Janeiro, Tribunal de Contas do Estado do Rio Grande do Norte, Tribunal de Contas do Estado do Rio Grande do Sul, Tribunal de Contas do Estado de Rondônia, Tribunal de Contas do Estado de Roraima, Tribunal de Contas do Estado de Santa Catarina, Tribunal de Contas do Estado de São Paulo, Tribunal de Contas do Estado de Sergipe, Tribunal de Contas do Estado do Tocantins, Tribunal de Contas do Distrito Federal; 4 (quatro) são Tribunais de Contas dos municípios: Tribunal de Contas dos Municípios do Estado da Bahia, Tribunal de Contas dos Municípios do Estado do Ceará (extinto em 2017), Tribunal de Contas dos Municípios do Estado de Goiás, Tribunal de Contas dos Municípios do 
Estado do Pará; e, 2 (dois) são Tribunal de Contas do Município: São Paulo e Rio de Janeiro ${ }^{10}$.

Não obstante, o Termo de Ajustamento de Gestão, ferramenta de viés consensual, robustece a atribuição fiscalizatória das Cortes de Contas. Todavia, percebe-se que existem 14 Tribunais que ainda não adotaram esta ferramenta, quais sejam: os Tribunais de Contas dos Estados de Alagoas; Amapá; Bahia; Ceará; Distrito Federal; Maranhão; Pará; Rio de Janeiro; Roraima; São Paulo; Tocantins. Os Tribunais de Contas do Município de São Paulo. O Tribunal de Contas dos Municípios da Bahia e o Tribunal de Contas da União.

Os Tribunais de Contas Estaduais que adotaram o TAG são em número de 19: Acre (Lei Orgânica do Tribunal de Contas do Estado do Acre Lei Complementar Estadual o 38, de 27 de dezembro de 1993. Art. 106-A. Acrescido pela Lei Complementar $n^{\circ}$ 259, de 29 de janeiro de 2013); Amazonas (Inciso XXVII acrescentado pelo artigo $1^{\circ}$ da Lei Complementar $n^{\circ}$ 120, de 13 de junho de 2013, arts. 42 - A e 42 - B); Espírito Santo (Regimento Interno: Resolução TC № 261, de 4 de junho de 2013, art. 1ํ, § 4º, Inciso XXXVIII e art. 14); Goiás (Lei oํ 16.168, de 11 de dezembro de 2007, que trata da lei orgânica do Tribunal de Contas do Estado de Goiás (TCE-GO), foi alterada pela Lei no 17.260 , de 26 de janeiro de 2011, que se limitou a implantar, no art. 110-a, o Termo de Ajustamento de Gestão); Mato Grosso (Lei Complementar oㅡ 486, de 7 de janeiro de 2013, que trouxe alterações em sua Lei Orgânica (Lei Complementar no 269, de 22 de janeiro de 2007), conforme Inc. XIX, do art. 1․ artigos 42-a, 42-b e 42-c); Mato Grosso do Sul (Lei Complementar ㄲo 160, de 2 de janeiro de 2012. art. 25-a); Minas Gerais (Lei Complementar no 120, de 15 de dezembro de 2011 - que dispõe sobre a organização do Tribunal de Contas, incluindo os arts. 93-A e 93-B na Lei Complementar Estadual no 108, de 17 de janeiro de 2008);

\footnotetext{
${ }^{10}$ Enfatize-se quanto aos níveis de competência: O Tribunal de Contas da União é órgão responsável pelo controle externo do governo federal, auxilia o Congresso Nacional e acompanha a execução orçamentária e financeira do país. Contribui para a boa Administração Pública federal, fiscalizando a aplicação dos recursos federais. Já os Tribunais de Contas dos Estados são órgãos estaduais voltados à análise de contas do respectivo Estado e de todos os municípios e órgãos jurisdicionados. Os Tribunais de Contas dos Municípios são órgãos estaduais que analisam as contas dos municípios integrantes de determinado Estado. Os Tribunais de Contas do Município, do Rio de Janeiro e de São Paulo, são órgãos municipais incumbidos da análise de contas do respectivo município. Outrossim, com o advento da Constituição Federal de 1988, ficou vedada a criação de novos tribunais municipais.
} 
Paraná (Lei Complementar 194 - 13 de abril 2016. art. 1o do §5º); Piauí (Resolução PI no 10, de 07 de abril de 2016); Rio Grande do Norte (Lei Complementar no 464, de 5 de janeiro de 2012, art. 122); Rondônia (Resolução no 246/2017/TCE-RO); Santa Catarina (Resolução no TC-137/2017, que determina a remessa de Projeto de Lei à Assembleia Legislativa para incluir na Lei Orgânica no 202/2000 os arts. 36-A e 36-B); Sergipe (Lei Complementar no 205, de 6 de julho de 201, art. 52 e Regimento Interno, arts 122 a 130).

Destaque-se que os Tribunais de Contas dos Estados da Paraíba (Resolução ํo 05/2007, art. 7ㅇ); Pernambuco (Lei Estadual ํㅜ 14.725, de 9 de julho de 2012, art. 48-A) e Rio Grande do Sul (Resolução no 1028/2015: Regimento Interno do TCE/RS, art. 142), que adotaram o termo com mesmo teor e objetivos, contudo com nomenclaturas distintas. Na Paraíba o termo é denominado de Pacto de Adequação de Conduta Técnico- Operacional. Em Pernambuco denomina-se Termo de Ajuste de Gestão. Já no TCE do Rio Grande do Sul a denominação é Termo de Adoção de Providências - TAP.

No âmbito dos Tribunais de Contas Municipais que adotaram o TAG têm-se: Goiás (Lei no 15.958, de 18 de Janeiro de 2007, art. 44-A, acrescido pela Lei oㅜ 19.990, de 22-01-2018), Pará (Regimento Interno TCM/PA, ato no 16/2013. Título VI, arts. 147 a 158).

Outrossim, seria de muito valor que os respectivos TAGs fossem criados por lei e não apenas por meio de norma infralegal (Regimento Interno/Resolução) para conferir uma maior segurança jurídica aos TCs que assim não o fizeram: TCE/PI, TCE/PB, TCE/ES, TCE/RS, TCE/RO e TCM/RJ.

No Tribunal de Contas do Município do Rio de Janeiro adotou-se o acordo através de Plano de Ação que consta no Manual de Auditoria Governamental, itens 202 a 207, aprovado por meio da Deliberação no 229/2016, oriundo da NAG 48-05, é o documento, preenchido pelo gestor do órgão/entidade auditada, quando notificado da decisão do plenário, que explicita as medidas que serão tomadas para fins de cumprimento das determinações/recomendações e/ou para dirimir os problemas apresentados. O Plano de Ação, dessa forma, distingue-se do TAG, por este ser mais cogente, no qual dispõe de mais formalização (RIO DE JANEIRO, 2017, p. 57-59). 
Disto extrai-se que dos 33 (trinta e três) Tribunais de Contas pátrios, só a minoria 14 (catorze) não adotou o TAG. Atualmente 16 (dezesseis) Tribunais de Contas estaduais mais 3 (três) municipais e do Município utilizam o TAG, demonstrando, assim, que este mecanismo vem adquirindo espaço, como uma nova forma de pensar das Cortes de Contas, aprimorando o controle fiscalizatório exercido por elas, além de concretizar o fortalecimento da democracia e, consequentemente, o bem-estar social.

\section{CASOS DE APLICABILIDADE DO TAG PELO TRIBUNAL DE CONTAS DO ESTADO DE SERGIPE}

A precitada Lei Orgânica do Tribunal de Contas do Estado de Sergipe (Lei Complementar Estadual n. .205 , de 06 de julho de 2011 ${ }^{11}$ ) trata, em seu art. 52, do Termo de Ajustamento de Gestão. O Regimento Interno do TCE/SE, RI/TCE-SE (SERGIPE, 2011) estabelece, nos seus arts.12212 a 130, o procedimento para a celebração de um TAG, que, como já exposto, pode ser aplicado em casos que apresentam irregularidades sanáveis na execução orçamentária, financeira, administrativa ou operacional, podendo ser utilizado em qualquer momento da instrução processual.

O TAG revela-se como um instrumento cuidadoso e moderno de gestão e refuta qualquer possibilidade de que este possa ocasionar qualquer prejuízo à Fazenda Pública, traz-se à colação o contido nos $\S \S 5^{\circ}$ e 6ํำ do art. 52 da referida Lei Complementar Estadual (LCE) n.․․ 205/2011 13 .

\footnotetext{
${ }^{11}$ A autora desta Tese participou da Comissão de elaboração da Lei Orgânica e do Regimento Interno do TCE/SE, Anexo II, p. 228.

${ }^{12} \S 1^{\circ} \mathrm{A}$ assinatura do TAG somente é permitida para o equacionamento de falhas ou irregularidades sanáveis, sendo o mesmo incabível para vícios em que se constate má-fé, dolo do gestor ou que revelem, em tese, improbidade administrativa. $\S 2^{\circ}$ No caso do controle de irregularidades que importem em dano ao erário, a assinatura do TAG, em nenhuma hipótese, pode resultar em diminuição do valor do débito ou glosa regularmente apurados.

${ }^{13} \S$ 50 A celebração de TAG não pode implicar, de nenhuma forma, em renúncia de receitas pertencentes ao Erário. $\S 6$ N Não cabe a celebração de TAG para atos e/ou situações que configurem ato doloso de improbidade administrativa.
} 
A titularidade da propositura do TAG, no âmbito do TCE/SE, está tripartida, entre a Presidência da Corte, o Conselheiro-Relator ou o Ministério Público Especial, obrigando a audiência e concreta participação do Ministério Público Especial e da Auditoria. Convém ressaltar que, em todas as esferas desse procedimento administrativo, o que se apresenta é um avanço democrático-institucional, como

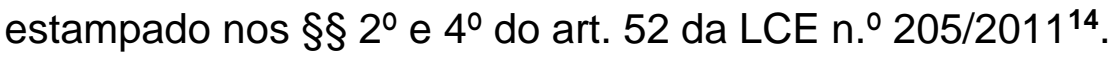

O art. 122, § 4, do RI/TCE-SE assinala que são partes obrigatórias do TAG: O gestor responsável, o relator, o representante do Ministério Público Especial e o representante da Auditoria.

Quando do firmamento do TAG, nos termos do art. $52, \S 1^{\circ}$ da Lei Orgânica do TCE/SE e do $\S 5$ do art. 122 do Regimento Interno do Tribunal de Contas do Estado de Sergipe (RI-TCE/SE) devem constar os seguintes elementos: "A identificação precisa da obrigação ajustada e da autoridade responsável pelo adimplemento da obrigação"; "[...] a estipulação do prazo para o cumprimento da obrigação"; "[...] a expressa adesão de todos os signatários às suas disposições"; "[...] as sanções a serem aplicadas em caso de inadimplemento da obrigação, especificando-se expressamente o valor da multa a ser aplicada em caso do seu descumprimento." Ressalte-se que para a validade jurídica do TAG se faz imprescindível a sua homologação pelo Plenário do Tribunal.

O procedimento inicia-se através da atuação do relator, de ofício ou aceitando o requerimento do Ministério Público de Contas, da parte interessada ${ }^{15}$, ou, também, por meio do ato da presidência. Logo após, o relator ordenará os atos necessários para a realização de audiência para celebração do TAG. De outro modo, reza o parágrafo único do art. 124 do RI-TCE/SE que o pedido de audiência para a celebração do TAG pode ser indeferido pelo relator e é cabível recurso de agravo para a respectiva Câmara, no prazo de 10 (dez) dias contados a partir da comunicação do indeferimento do pedido.

\footnotetext{
${ }^{14}$ Art. $52[\ldots] \S 2^{\circ}$ A iniciativa de proposição do TAG cabe à Presidência, ao Conselheiro-Relator ou ao Ministério Público Especial. § 4ํㅡ É obrigatória a audiência e efetiva participação do Ministério Público Especial e da Auditoria em todas as fases do procedimento administrativo para a celebração do TAG. 15 Nos termos do $\S 3^{\circ}$ do art. 122 do RI/TCE/SE, entende-se como parte interessada aquela juridicamente legitimada ao equacionamento da falha e/ou irregularidade objeto do TAG.
} 
Nos termos do art. 126, caput e seus parágrafos ${ }^{16}$, do Regimento Interno do TCE/SE, as partes que integram o potencial conflito serão intimadas por prazo de cinco dias de antecedência, exceto na ocorrência espontânea de aceitação de menor prazo, para estarem presentes na sede do TCE/SE17. Então, o Ministério público indica seu representante e o Auditor será escolhido mediante sorteio. Durante o procedimento a parte interessada (gestor) pode requerer o acompanhamento de assessores. Além disso, o Relator pode convidar técnicos do tribunal para integrarem a audiência de conciliação, a qual pode ser conferida o caráter de audiência pública, contudo, exige-se a tomada das providencias necessárias para o ato.

No caso de celebração de conciliação em relação aos termos do TAG ${ }^{18}$, ocorrerá a assinatura por todas as partes obrigatórias. O Termo será, então, sujeito à apreciação do tribunal pleno, em no máximo duas sessões, após sua assinatura. A

${ }^{16}$ Art. 126. Os participantes das discussões do TAG serão intimados da audiência de que trata o artigo anterior com 5 (cinco) dias de antecedência, podendo tal prazo ser diminuído caso haja adesão espontânea de todas as $p$ artes envolvidas a prazo menor. $\S 1^{\circ}$ Caso não haja ainda representante do Ministério Público Especial oficiando no processo a que se refere o TAG, a intimação será dirigida ao Procurador-Geral do Ministério Público Especial, que irá pessoalmente à audiência, vinculando-se ao processo, ou, desde já, designará o membro do parquet especial que nele oficiará e na audiência de conciliação do TAG. $2^{\circ} \mathrm{O}$ representante da Auditoria será escolhido mediante sorteio. $3^{\circ} \mathrm{A}$ A parte interessada poderá contar na audiência com o apoio técnico de auxiliares, assessores, advogados e/ou

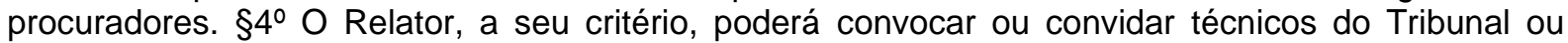
pessoas da Sociedade, de modo a enriquecer o debate desenvolvido na audiência na qual será discutido o TAG. $5^{\circ}$ De ofício, ou a requerimento de quaisquer dos legitimados, o Relator poderá dar à audiência de conciliação o caráter de audiência pública; e neste caso, será providenciada a estrutura e publicidade necessárias para que representantes da sociedade civil possam acompanhá-la.

${ }^{17} \mathrm{RI}-\mathrm{TCE} / \mathrm{SE}$, art. 125: A audiência realizar-se-á na sede do Tribunal de Contas do Estado de Sergipe, com a presença do Relator, da parte interessada, do membro do Ministério Público Especial no processo e do representante da Auditoria.

${ }^{18} \mathrm{RI}$-TCE/SE, art. 127 e parágrafos: Conciliadas as disposições para o saneamento da falha, e estando concordes o Relator, o gestor responsável, a Auditoria e o Ministério Público Especial quanto ao prazo assinalado, será lavrado o competente Termo de Ajustamento de Gestão, que será por todos assinado e levado à apreciação do Tribunal Pleno. 1 $^{\circ} \mathrm{O}$ Termo de Ajustamento de Gestão devidamente lavrado nos termos deste Regimento será levado a conhecimento e apreciação do Egrégio Plenário até no máximo de duas sessões subsequentes à sua lavratura. §2 $\mathrm{A}$ assinatura do TAG importa em reconhecimento da falha pela parte interessada e renúncia expressa ao seu direito de discuti-la administrativamente no âmbito do Tribunal de Contas do Estado de Sergipe. §3ํㅡ A assinatura do TAG pelos membros do Ministério Público Especial e da digna Auditoria significa sua adesão às cláusulas do documento, e será considerada como pronunciamento favorável à decisão Plenária que eventualmente chancele o Termo de Ajustamento, nos termos do art. 128 deste Regimento. $\$ 4^{\circ} \mathrm{A}$ assinatura do TAG implica em renúncia ao direito de recorrer da decisão Plenária que eventualmente a acolha. $\S 5^{\circ}$ Em qualquer caso, havendo ou não assinatura de TAG, será lavrada a ata da audiência, que será assinada pelo Relator, pela parte interessada e pelos membros da Auditoria e do Ministério Público Especial oficiantes. $6^{\circ} \mathrm{Em}$ não havendo conciliação, o processo seguirá o rito normal regimentalmente previsto. 
assinatura do TAG resulta em renúncia ao direito de recorrer e torna obrigatória a aderência aos seus ditames. Diante da inocorrência de conciliação, lavra-se a ata respectiva que deve, também, ser assinada por todos e o processo segue o seu rito normal.

$\mathrm{Na}$ fase de execução do TAG o gestor fica responsável em informar o efetivo cumprimento dos seus termos e execução ao tribunal correspondente, conforme devidamente lavrado em ata, o que resultará na constatação de saneamento da irregularidade.

Impende acrescentar, que o TAG pode ser aplicável em casos de controle dos certames licitatórios. Em parceria com medidas cautelares, O TAG atua com excelência para sanar falhas em processos licitatórios e promover a continuidade e eficiência do certame, visto que, especialmente, na esfera da prestação de serviços públicos, o objetivo principal da Administração Pública é sua continuidade e eficácia. Desse modo, ele atua como um mecanismo de boa-fé e respeito à população, com caráter pedagógico, refutando o viés punitivo para elidir falhas.

O Termo regula os controles tempestivos de execução e sanções oportunas, em caso de descumprimento. Em princípio, o prazo para cumprimento do TAG é improrrogável, podendo, em caso excecionalíssimo ser aditado uma única vez, mediante nova decisão do Pleno ${ }^{19}$. Utilizado sempre que possível, como meio de popularizá-lo, integrando os gestores, o Tribunal de Contas e o Ministério Público de Contas.

Homologado o TAG, o processo respectivo ficará sobrestado até o exaurimento do prazo para o cumprimento das matérias nele envolvidas. Quando executadas adequadamente as exigências propostas no TAG, livrar-se-á o gestor da obrigação contraída, como disposto no $\S 7^{\circ}$ do art. 52 da multicitada Lei Orgânica, in

\footnotetext{
${ }^{19}$ RI-TCE/SE, art. 128 e parágrafos: Homologado o TAG pelo Pleno, suas disposições serão objeto de decisão interlocutória, que encampará todas as obrigações a justadas, assim como os prazos conciliados e as cominações em caso de descumprimento. $§ 1^{\circ} \mathrm{O}$ gestor responsável será intimado da decisão de que trata este artigo, correndo o prazo para cumprimento a partir da data da intimação. §2º O prazo para cumprimento do TAG é, em princípio, improrrogável, podendo, em caráter excepcional, ser aditado uma única vez, mediante nova decisão do Pleno. §3으 O relator da decisão será o mesmo que participo u da lavratura do TAG. §4 Homologado o TAG, o processo respectivo ficará sobrestado até o exaurimento do prazo para o cumprimento das matérias nele envolvidas. §5ํㅜ Rejeitado o TAG pelo Pleno, este restará sem nenhum efeito, e voltará o processo ao seu rito normal.
} 
verbis: "Uma vez observadas todas as disposições do TAG, pode ser dada quitação ao gestor responsável tanto quanto ao seu cumprimento, como quanto ao saneamento da falha que ensejou a sua lavratura". O art.130 do RI-TCE/SE pontua que o controle informatizado dos TAGs firmados e chancelados pelo TCE/SE, bem como o acompanhamento dos respectivos prazos é de responsabilidade da Diretoria Técnica.

Decerto, os gestores receberão os efeitos do TAG, tanto de forma positiva, quanto de forma negativa. Em relação ao particular (contratado) este pode integrar o termo, se integrar a obrigação contratual preteritamente adotada com a Administração, e anuir com os seus ditames, possibilizando, assim, a sua participação direta nos termos ajustados.

Diante do quanto explanado, o Termo de Ajustamento de Gestão - TAG para as Cortes de Contas, funciona, modus in rebus, com igual intuito ao Termo de Ajustamento de Conduta - TAC do Ministério Público ou, como exemplos, os ajustes de conduta da CVM (Comissão de Valores Mobiliários); ANEEL (Agência Nacional de Energia Elétrica); ANTT (Agência Nacional de Transportes Terrestres); ANS (Agência Nacional de Saúde) e ANATEL (Agência Nacional de Telecomunicações).

O TAG é, geralmente, aplicado em decorrência das auditorias de conformidade (inspeções) e, notadamente, das auditorias operacionais, resultando em celeridade processual, em observância aos princípios da eficiência, eficácia, efetividade e economicidade desejáveis no âmbito da Gestão Pública, se consubstanciando num forte mecanismo de alcance dos direitos fundamentais dos administrados, como se verá mais adiante.

\section{CONCLUSÃO}

Com as transformações da atuação do Estado e da Administração, a adoção do consenso tem sido cada vez mais discutida e analisada para a solução de problemas. Neste viés, surge o Termo de Ajustamento de Gestão, como ferramenta de fortalecimento do exercício do controle externo, de competência dos Tribunais de Contas, tendo em vista o princípio da eficiência na administração pública, nos moldes 
da Constituição Republicana atual. Trata-se de um acordo firmado no plano das Cortes de Contas como uma proposta substitutiva à coerção administrativa voltada para a correção de rumos dos atos de gestão, desde que não eivados de dolo ou má fé.

Os TCs sentiram a necessidade de tornar mais ágil a solução de desconformidades de ações de gestores e, embora, não previsto em texto legal, partiram para obterem soluções, mediante termos de compromisso, que, se não cumpridos, acarretariam a aplicação de sanções para os gestores inadimplentes. Isto dentro do próprio processo de auditoria/inspeção. Essa mudança nada mais é do que uma forma de ativismo administrativo, por ser ação consensual não oriunda de norma legal, mas, sim, fundada em princípios gerais de direito, privilegiando, desse modo, a justiça social.

Assim, a adoção dos Termos de Ajustamentos de Gestão (em sede de Tribunais de Contas) se torna cada vez mais real e efetiva através da evolução da estrutura estatal com vistas à solução de conflitos. De um lado está o princípio da negociação, como uma prática contínua, no cotidiano social. Por outro, o instituto do Termo de Ajustamento de Gestão, previsto ${ }^{20}$ nas Leis Orgânicas, Regimento Interno e Resoluções dos Tribunais de Contas, têm objetivo idêntico, qual seja: a solução e a celeridade para evitar conflitos.

O TAG surgiu como uma ferramenta para harmonizar e promover a celeridade de decisões, a oitiva democrática dos gestores e o consenso, para evitar litígios e processos infindáveis, assegurando a adequação e a melhoria da gestão pública. Com o objetivo de prevenir ou sanar irregularidades presentes no caminho da Administração, enfraquecendo a aplicação literal e ineficiente da lei.

Foi importante desmistificar o fato do TAG ser considerado prévia e equivocadamente como inconstitucional e ilegal, entendimento que não procede, posto que a Teoria dos Poderes Implícitos, com alicerce principiológico de cunho

${ }^{20}$ A não inclusão do TAG no bojo normativo dos Tribunais de Contas, não impede a aplicação e o exercício do mesmo, em razão de mandamento constitucional implícito que legitima as Cortes de Contas para tal ajuste. Todavia esta pesquisa manifesta-se pela previsão nos regramentos normativos dos Tribunais de Contas, eis que a sua normatização Ihe conferirá maior autenticidade a segurança jurídica. 
constitucional, arts. 70 e 7121, bem como legislação infraconstitucional, dá aos TCs, no uso de seu poder de fiscalização, a fundamentação para que possam exercitar o TAG nos atos de gestão pública que redundam em erro ou até dano. Assim, as considerações acima provam a constitucionalidade da figura do TAG.

Há um vasto número de questões submetidas à deliberação dos Tribunais de Contas, no exercício do controle externo da Administração Pública, que trata do acolhimento ou não do TAG, considerado por muito tempo como prática puramente ativista.

Contudo, o Código de Processo Civil, bem como a Lei Federal ํo 13.655/2018, quando tratam de transação e compromisso, dão as ferramentas básicas e necessárias para a prática do TAG. Neste mesmo raciocínio, tem-se que a Lei Complementar Estadual de Sergipe, número 205/2011 (Lei Orgânica do TCE/SE), já o havia instituído como uma ferramenta legal.

A despeito disso, o TAG, por sua própria essência, continua, na sua aplicação, como instrumento importante do ativismo administrativo, posto que permite, através dos compromissos firmados no seu bojo, ir além do que a Lei literalmente dispõe, cuja finalidade se volta para a concretização de direitos dos cidadãos e em benefício destes, indo além da literalidade da lei, levando-se em consideração que o julgador de contas não detém o conhecimento absoluto acerca de todos os fatos que circundam a Pública Administração, sejam eles de ordem técnica, científica, orçamentária e etc.

Evidencia-se que o Supremo Tribunal Federal tem almejado, por meio de audiências públicas e da aceitação de amicus curiae, fornecer especial atenção aos demais segmentos da sociedade. Logo, suas decisões ganham grande relevância para promover a garantia de direitos fundamentais e satisfazer omissões dos demais Poderes, quais sejam, Legislativo e Executivo, principalmente no que se refere à demonstração de questões com grande repercussão social, onde o Parlamento não deseja envolver-se para evitar qualquer prejuízo quanto a sua popularidade.

${ }^{21} \mathrm{CF} / 88$ : art. 71, IX - assinar prazo para que o órgão ou entidade adote as providências necessárias ao exato cumprimento da lei, se verificada ilegalidade. 
Neste viés, o ativismo judicial demonstra um ato volitivo dos membros do Judiciário em decidir ultrapassar o quanto expresso no ordenamento jurídico ordinário, em especial, interpretando a Constituição Federal, através da aplicação dos princípios, considerados expressos ou implícitos, ali contidos, dando-Ihes contorno de normatização.

Em linhas gerais, este trabalho possibilitou aferir que os Termos de Ajustamento de Gestão firmados pelo TCE/SE agem em prol do direito social à educação, bem como fomentam o direito à informação, dentre outros direitos sociais.

Justifica também a existência do TAG o fato deste conferir à sociedade melhor conhecimento do que são os TCs e a sua essencialidade para o controle das contas públicas que é elemento basilar para que o Estado Democrático de Direito se torne mais evidente, porque desse conhecimento mais se afirma a essencialidade da cidadania para que os direitos da sociedade sejam cada vez mais respeitados através da simbiose: Tribunal de Contas, cidadão e fiscalização dos atos públicos.

Os Tribunais de Contas estão se modernizando, enfim, aproximando-se da sociedade, dando celeridade às suas decisões, seja através de determinações, seja através do consenso (desde que o caso permita) dada a utilização de estratégias e de algumas táticas para a sua consecução, nos moldes da Teoria Certeauniana. Pensar o controle externo apenas como aquele "que vigia e pune", como tão-só sancionador, é retroceder; é buscar a revalidação de modelos de Estado já experimentados e superados. É, por assim dizer, caminhar em linha diametralmente oposta à evolução. Este é o grande papel dos TAGs: transigir ao invés de unicamente sancionar, permitindo aos TCs exercer o controle através do consenso, possibilitando a tutela de direitos sociais e fundamentais.

\section{REFERÊNCIAS}

BARROSO, Luís Roberto. Constituição, democracia e supremacia judicial: direito e política no Brasil contemporâneo. In: FELLET, André Luiz Fernandes; PAULA, Daniel Giotti de; NOVELINO, Marcelo. (org.), As novas faces do ativismo judicial. 2. ed. Salvador: Jus Podivm, 2013. 
BONAVIDES, Paulo. A Constituição Aberta. 3 ed. São Paulo: Malheiros, 2004.

BORBA, Joselita Napuceno. Repensando o termo de ajustamento de conduta (TAC): vicissitudes de sua desconstituição. Revista LTr: legislação do trabalho e Previdência Social, São Paulo, v. 76, n. 11, p. 1.299-1.307, nov. 2012.

BRASIL. Constituição Federal do Brasil (1988). São Paulo: Revista dos Tribunais, 2010a.

BRASIL. Lei no 7.347 de 24 de julho de 1985. Disciplina a ação civil pública de responsabilidade por danos causados ao meio-ambiente, ao consumidor, a bens e direitos de valor artístico, estético, histórico, turístico e paisagístico e dá outras providências. Disponível em: < http://www.planalto.gov.br/CCivil_03/leis/L7347orig.htm>. Acesso em: 05 set. 2017.

BRASIL. Lei Federal no 8.069 de 13 de julho de 1990a. Dispõe sobre o Estatuto da Criança e do Adolescente e dá outras providências. Disponível em: < http://www.planalto.gov.br/Ccivil_03/leis/L8069.htm>. Acesso em: 10 set. 2017.

BRASIL. Lei 8.078 de 11 de setembro de 1990b. Dispõe sobre a proteção do consumidor e dá outras providências. Disponível em: < http://www.planalto.gov.br/ccivil_03/Leis/L8078.htm>. Acesso em: 10 set. 2017.

BRASIL. Lei Complementar no 101, de 4 de maio de 2000. Estabelece normas de finanças públicas voltadas para a responsabilidade na gestão fiscal e dá outras providências. Disponível em: <http://www.planalto.gov.br/ccivil_03/Leis/LCP/Lcp101.htm>. Acesso em: 02 fev. 2018.

BRASIL. Lei no 13.105, de 16 de março de 2015. Código de Processo Civil. Disponível em: <http://www.planalto.gov.br/ccivil_03/_ato20152018/2015/lei/l13105.htm>. Acesso em: 29 abr. 2018.

BRASIL. Lei no 13.655, de 25 de abril de 2018. Inclui no Decreto-Lei no 4.657, de 4 de setembro de 1942 (Lei de Introdução às Normas do Direito Brasileiro), disposições sobre segurança jurídica e eficiência na criação e na aplicação do direito público. Disponível em: <http://www.planalto.gov.br/ccivil_03/_ato20152018/2018/lei/L13655.htm>. Acesso em: 27 abr. 2018.

CERTEAU, Michel de. A invenção do cotidiano: artes de fazer. Trad. Ephraim Ferreira Alves. 3. ed. Petrópolis/RJ: Editora Vozes, 1998.

FERRAZ, Luciano. Termo de Ajustamento de Gestão (TAG): do sonho à realidade. In: Revista Brasileira de Direito Público - RBDP. Belo Horizonte, ano 08, n. 31. out./dez., 2010. 
GIL, Antônio Carlos. Como elaborar projeto de pesquisa. 5. ed. São Paulo: Atlas, 2010.

HABERMAS, Jürgen. The theory of communicative action. Vol 2. Lifeworld and sistem: A critique of functionalist reason. Boston: Beacon Press, 1987.

HABERMAS, Jürgen. Direito e Democracia: entre facticidade e validade. Trad. Flávio Beno Siebeneichler. v. 01. Rio de Janeiro: Tempo Brasileiro, 1997.

KOERNER, Andrei. Ativismo Judicial? Jurisprudência constitucional e política no STF pós-88. Novos estud. - CEBRAP, São Paulo, n. 96, jul. 2013.

SERGIPE. Tribunal de Contas do Estado de Sergipe. Institui a Lei Orgânica do Tribunal de Contas do Estado de Sergipe, e dá providências correlatas. Lei Complementar Estadual no 205, de 06 de julho de 2011a. Disponível em: < https://www.tce.se.gov.br/Docs\%20Institucional/Lei_organica.pdf>. Acesso em: 10 set. 2017.

SERGIPE. Regimento interno do Tribunal de Contas de Sergipe, aprovado pela Resolução no 270/2011b. Disponível em: < https://www.tce.se.gov.br/Docs\%20Institucional/regimento2012.pdf>. Acesso em: 10 set. 2017.

SERGIPE. Nova Legislação do Tribunal de Contas do Estado de Sergipe. $1^{\text {a }}$ edição. Aracaju: CL, 2011c.

SOBRAL DE SOUZA, Patrícia Verônica Nunes Carvalho. É possível mediação em sede de Tribunais de Contas? In: SILVA, L. A. M. G. da, org. Mediação de Conflitos. São Paulo: Atlas, 2013.

WILLIAMSBURG, Declaração de Direitos de Virgínia. 12 de junho de 1776. Disponível em: <http://www.dhnet.org.br/direitos/anthist/dec1776.htm>. Acesso em 15 jan. 2018. 